\title{
REVIEW OF LEARNING OUTCOMES DEVELOPED FOR GRADUATE ATTRIBUTES
}

\author{
Beach D; McCahan, S M \\ Faculty of Applied Science \& Engineering, University of Toronto, Ontario Canada \\ david.beach@mail.utoronto.ca; mccahan@mie.utoronto.ca
}

\section{INTRODUCTION}

A project is underway to develop valid analytic rubrics that can be used to assess learning outcomes related to the CEAB graduate attributes in several key areas: investigation, design, problem solving, communication and teamwork. This is part of a larger program funded by the Higher Education Quality Council of Ontario (HEQCO) to investigate valid methods for assessing learning outcomes. As a first step in this project, a review of existing learning outcomes related to these areas has been conducted and rubrics for each indicator have been drafted.

\section{DEVELOPMENT PROCESS}

There are many specific learning outcomes (i.e. indicators) that have been suggested for the attributes under investigation, or related global learning outcomes. These come from sources such as the VALUE Program, the Tuning project, Canadian engineering institutions and others. ${ }^{1-6}$ In the first phase of this project indicators from these and other sources have been compiled and organized into a comprehensive list.

One of the first obstacles that became apparent was the differences in the terminology used in this field. The use of terms such as competency, indicator, skill, outcome, criteria and global outcome was inconsistent. We found that to create a clear coherent integrated system required defining learning outcome levels and translating the different systems into a single hierarchy. We settled on the use of a three level system where "indicator" is used to describe the most specific learning outcomes which are measurable at the assignment or exam level; "Global outcome" to describe learning outcomes that best describe learning at the course level or through a set of courses; and finally, at the top level, we used "competency" which translates to "attribute" in the CEAB terminology.

One of the other important complexities we had to resolve was the relationship between problem analysis (or problem solving) and design outcomes. There is no clear boundary between open-ended problems that are often addressed as design problems and purely close-ended problems characteristically addressed through problem solving methodologies. A substantially constrained design problem can become virtually close-ended. Similarly, a problem that is close-ended in ideal circumstances can become open-ended when it is under-defined or when circumstances do not allow the application of a routine solution. Adding to this complexity, many of the existing learning outcome systems do not explicitly recognize "design" as a separate entity, but instead include problem analysis and critical thinking categories. Many of the critical thinking indicators in these systems, we, as engineers, recognize as design outcomes. We carefully examined the lists of indicators, and based on the CEAB attribute definitions assigned the indicators to either the "problem analysis" or "design" category. However, we recognize that this is somewhat arbitrary and open to reinterpretation.

In examining the list of indicators that resulted from this process, we discovered that many of the systems did not include outcomes related to reflection. There is research to suggest that reflection is important to effective learning. ${ }^{7,8}$ So in this instance, and where we observed other obvious gaps, we added indicators to make the list more complete.

\section{RESULTS}

This phase of the project resulted in a comprehensive list of learning outcomes (indicators) in communication, teamwork, investigation, design, and problem analysis. Duplicate or redundant indicators were removed from the list to keep it as concise as possible. In addition, the indicators were organized into global outcome categories. Some of the systems reviewed already had global outcome categories, but for the purposes of creating a comprehensive, but well organized, list we identified common global categories and reorganized the indicators into these categories. The global outcomes evident from the indicator list are useful because they help to define the high level attributes (or competencies) more clearly.

One of the interesting observations from this list is the number of different global outcomes that are evident from the comprehensive indicator list. In problem solving alone, we compiled 29 unique indicators in eight different global outcome areas: The student demonstrates the ability to

- ... define the problem

- ... identify strategies or solution processes

- ... propose a solution process

- ... implement a solution process

- ... evaluate the results

- ... reflect on the solution

- ... reflect on the problem-solving process

- ... use advanced problem-solving skills

Similar lists were developed for the 4 other attribute areas. Together these organized lists give a comprehensive view of our collective understanding of competency in these areas.

\section{CURRENT AND FUTURE WORK}

After completing the organized lists, draft analytic rubrics were developed. This entailed creating sets of descriptors for each indicator. The first drafts have four levels: fails, below expectation, meets expectation, and exceeds expectation. However, we recognize that a performance that meets expectation at a first year level may fail to meet expectation at the fourth year level. For this reason we are now working to create a graduated system of rubrics that describe expectations from the first year through to fourth year. We will be consulting with instructors to ensure that the levels are appropriate.

Next the rubrics will be implemented into courses. We expect the instructors to modify the indicators to some degree and the descriptors to fit the assessments in their course. However, the rubrics we have created will serve as a starting point. The rubrics will be evaluated for inter-rater reliability and validity during the following years of this project. The goal is to provide the community with resources they can adapt to their own institutional needs.

\section{ACKNOWLEDGEMENT}

This work is supported by the Higher Education Quality Council of Ontario (HEQCO) Contract \#12/13-RFP-006-06.

\section{REFERENCES}

1. VALUE: Valid Assessment of Learning In Undergraduate Education. http://aacu.org/value/rubrics/index.cfm, 2013. [Online; accessed 15Aug13].

2. Bulgarelli V, Lettmayr C, and Menéndez-Valdés J. The shift to learning outcomes: Policies and Practices in Europe. European Centre for the Development of Vocational Training, 2009.

3. The European Qualifications Framework for Lifelong Learning. http://ec.europa.eu/education/pub/pdf/general/eqf/leaflet_en.pdf. [Online, accessed 15Aug13].

4. Council of Europe. Convention on the Recognition of Qualifications concerning Higher Education in the European Region. http://conventions.coe.int/Treaty/Commun/-

QueVoulezVous.asp?NT =165\&CM=8\&DF=10/17/2007\&CL=ENG, 1999. [Online; accessed 21 August 2013].

5. Organization for Economic Cooperation and Development. AHELO: Assessment of Higher Education Learning Outcomes. http://www.oecd.org/edu/skills-beyond-school/skills-beyond-school/AHELO\%20Brochure.pdf, 2012. [Online; accessed 21 August 2013]. 6. Engineering Graduate Attribute Development Project (EGAD). http://egad.engineering.queensu.ca/?page_id=1207, 2011 [Online: accessed 14 April 2014].

7. Woods DR, Kourti T, Wood PE, Sheardown H, Crowe CM, and Dickson JM. Assessing Problem-Solving Skills-Part 1: The Context for Assessment. Chemical Engineering Education, Fall:300-307, 2001. 8. Woods DR, Kourti T, Wood PE, Sheardown H, Crowe CM, and Dickson JM. Assessing Problem-Solving Skills-Part 2: Assessing the Process of Problem Solving. Chemical Engineering Education, Winter:60-67, 2002. 